\title{
Efficiency of savory (Satureja Khuzestanica Jamzad) essential oil on performance, carcass traits, some blood parameters and immune function of Male Ross 308 heat stressed broiler chicks
}

\author{
Mohammad Yadegari ${ }^{1}$, Hasan Ghahri ${ }^{1 *}$ and Mohsen Daneshyar ${ }^{2}$ \\ ${ }^{1}$ Department of Animal Science, College of Veterinary Medicine, Urmia Branch, Urmia, Iran \\ ${ }^{2}$ Department of Animal Science, Faculty of Agriculture, Urmia University, Urmia, Iran
}

E-mail: hasanghahri148@gmail.com

Received: 14.11.2019. Accepted: 05.12.2019

\begin{abstract}
To investigate the efficiency of savory essential oil on performance, organs relative weight, some blood parameters, immune response and hepatic enzymes of broiler chickens, a total 320 male Ross 308 chicks were allocated to four treatments and four replicates of twenty birds as a completely randomized design from. The variables whereas heat stress ( $34 \pm 2 \cdot \mathrm{C}$ for 8 hours) and different levels savory oil. The body weight gain (BWG), feed intake (FI) and feed conversion ratio (FCR) was recorded at continues weeks of the experiment. Relative weight of visceral organs was determined and blood serum glucose and activities of aspartate aminotransferase (AST), alanine aminotransferase (ALT), and alkaline phosphatase (ALP) were measured after blood sampling at 42 days old and plasma IgG immunoglobulin was quantified. Data showed that BW and FI increased with savory oil inclusion ( $p \leq 0.05$ ). Besides, the savory oil decreased the plasma glucose, AST and ALT and serum blood Ig G of heat stressed broilers, increased significantly $(p \leq 0.05)$ instead. In conclusion we may suggested that, the savory oil at $0.4 \mathrm{ml} / \mathrm{L}$ could improve economic proficiency in broiler flocks due to accumulation of minute advantages in greater BWG, FI, and improved immune system and lowered hepatic enzymes under heat stress condition.
\end{abstract}

Key words: Heat stressed broilers; Hepatic enzymes; Immune function; Performance; Savory essential oil

\section{Introduction}

Heat stress (HS) is one of the most important negative prepossessing of poultry growth factors and immune function in tropical countries, also at the warm seasons in clement countries that could be so much costly. The main concern of HS in young birds is depressed weight gain occurring mainly due to reduced feed intake and elevated energy spending to decrease body temperature (May and Lott 1992; Belay and Teeter 1993). The nutritional manipulations could be the cheapest way to outcome the harmful effects of heat stress. The general healthiness condition and performance of broilers exposed to heat-stressed environmental situations positively responded to supplementation diets with antibiotic growth promoters (Manner and Wang, 1991; Cabuk et al., 2006). Extracts and essential oils of some herbs received considerable interest in poultry feeding as a unique feed additive alternative to AGP (Suderman and Solikhah 2011; Zeinali et al. 2011). Savory (Satureja khuzistanica Jamzad) is a plant identified for its therapeutic effects in traditional medicine (Abdollahi et al., 2003). The upper (aerial) parts of savory plant concertedly include up to 3 percentage of an essential oil spectacularly rich in carvacrol (Khosravinia, 2016). Carvacrol is a phenolic, bitter tasting and caustic component with good stability demonstrating antioxidant and antimicrobial properties (Khoravinia, 2016). Correspondingly, it has been reported that savory essential oils have antioxidant and antibacterial effects mainly in experiments directed under standard directorial practices and normal environmental situations (Abdollahi et al. 2003; Radonic and Milos 2003; Azaz et al. 2002). Furthermore, there is some reports indicated that savory extract is beneficial in heat stress situation and helpful to overcome the harmful effects of mentioned stressor (Khoravinia, 2016). Hence the major aim of current study was to evaluate the efficiency of savory oil in drinking water on the performance, organs weight, immune response and hepatic enzymes of heat stressed broiler chickens.

\section{Materials and Methods}

Animals, managing and diets

The experiment was performed in the Faculty of Veterinary Medicine, Islamic Azad University, Urmia Branch, Urmia, Iran. A total 320 male Ross 308 chicks were allocated into the four treatments and four replicates of twenty birds as a completely randomized design from. Experimental birds aged from 21 to 42 days of age with average weight of $800 \pm 100 \mathrm{~g}$ were used and the treatments 
were included a control group with no heat stress (control+), control treatment under heat stress condition (control-) exposed at the temperature $34 \pm 2{ }^{\circ} \mathrm{C}$ for 8 hours day time, treatment containing $0.4 \mathrm{ml}$ savory essence mixed with drinking water within control+ and control- groups respectively and feed and water were offered ad-libitum throughout the experimental period. Arial part of savory plant was gathering from Urmia herbal farm and its essence was obtained at the Islamic Azad University, Urmia Branch herbal plant institute laboratory and was used.

The experimental diet was formulated to meet the requirements as established by Ross 308 guideline (Table 1) and the lighting program during the experimental period consisted of a period of $23 \mathrm{~h}$ light and $1 \mathrm{~h}$ of darkness.

Table 1. The nutrient composition and ingredients of experimental diets.

\begin{tabular}{llll}
\hline Ingredients (\%) & $\begin{array}{l}\text { Starter } \\
(\mathbf{1 - 1 0} \text { days) }\end{array}$ & $\begin{array}{l}\text { Grower } \\
\mathbf{( 1 1 - 2 4} \text { days) }\end{array}$ & $\begin{array}{l}\text { Finisher } \\
\text { (25-42 days) }\end{array}$ \\
Corn & 56.12 & 58.89 & 62.61 \\
Soybean meal (44\%) & 37.9 & 33.80 & 30.04 \\
Soy oil & 1.23 & 2.83 & 3.25 \\
L-lysine & 0.30 & 0.33 & 0.19 \\
DL-methionine & 0.18 & 0.23 & 0.17 \\
DCP & 2.13 & 1.88 & 1.74 \\
Oyster shell & 1.28 & 1.17 & 1.13 \\
Salt & 0.36 & 0.37 & 0.37 \\
Vit premix & 0.25 & 0.25 & 0.25 \\
Min premix & 0.25 & 0.25 & 0.25 \\
Analyzed compositions & & & \\
AMEn ${ }^{3}$ (kcal/kg) & 2845 & 2990 & 3060 \\
CP (\%) & 22.00 & 20.50 & 19.00 \\
Lysine (\%) & 1.38 & 1.30 & 1.10 \\
Methionine (\%) & 0.55 & 0.58 & 0.50 \\
Methionine + Cysteine (\%) & 0.92 & 0.92 & 0.82 \\
Calcium (\%) & 1.00 & 0.9 & 0.85 \\
Available phosphorous (\%) & 0.50 & 0.45 & 0.42 \\
Sodium (\%) & 0.16 & 0.16 & 0.16 \\
DCAD 4 & 222 & 201 & 192 \\
\hline
\end{tabular}

${ }^{1}$ Provided per kg of diet: vitamin A: $9000 \mathrm{IU}$; vitamin D: $2000 \mathrm{IU}$; vitamin E: $18 \mathrm{IU}$; vitamin K : 3 mg; vitamin B : 1.78 mg; vitamin B :6.6 mg; vitamin B 3126 : 3 mg; vitamin B12 : 0.015 mg; Niacin: 30 mg; Pantothenic acid: 10 mg; Biotin: 0.15 mg and Choline: $1500 \mathrm{mg}$.

${ }^{2}$ Provided per $\mathrm{kg}$ of diet: Cu: $10 \mathrm{mg}$; I: $0.99 \mathrm{mg}$; Fe: $50 \mathrm{mg}$; Mn:100 mg; Se: $0.08 \mathrm{mg}$; and Zn: $100 \mathrm{mg} .3 \mathrm{AMEn}$ : apparent metabolizable energy corrected for nitrogen.4 DCAD: dietary cation anion differences.

\section{Performance parameters}

Body weight gain (BWG) and feed intake (FI) were measured and feed conversion ratio (FCR) were calculated based on bird per day for each period of experimental plan.

\section{Organs relative weight}

At 42 day of age, two birds per pen were selected, weighed and slaughtered by decapitation to obtain the dressing and organs relative weights. The organs were consisted of breast, thighs, heart, liver, spleen bursa fabricius percentage of live body weight.

\section{Blood biochemical analysis}

Blood serum samples were collected on day 42 in sterile heparinised vacationers for analysis of ALT, AST, ALP and blood glucose. Exactly within 30 min right after blood collection, blood samples were centrifuged at $1,500 \times \mathrm{g}$ for 10 min. The blood plasma was harvested and stored at $-20^{\circ} \mathrm{C}$ until analysis. All biochemical analyses were assayed on an automated biochemical analyzer.

\section{IGg assay}

At 28,35 and 42 days of age, two birds per each pen were randomly selected, and blood serum samples were collected from the wing vein. Blood samples were allowed to clot in $+4^{\circ} \mathrm{C}$ and were centrifuged at $3,000 \times \mathrm{g}$ for 10 min before harvesting the serum. The blood serum samples were stored at $-20^{\circ} \mathrm{C}$ until they were analyzed. Additionally the blood serum concentrations of IgG were determined by ELISA test using micro titer plates and chicken-specific IgG ELISA quantization kits (Pars-Azmoon ßcommercial kits). The mentioned procedure was carried out according to the protocol of the producer, and absorbance was determined at $450 \mathrm{~nm}$.

\section{Statistical analysis}

The data collected were subjected to analysis of variance procedures appropriate for a completely randomized design by using the general linear model (GLM) procedures of SAS (2004). The statistical significance differences among treatments was comparison by using the Duncan's (1995) test.

\section{Results}

The effects of different treatments during the experiment on growth performance of broilers are shown in Tables 2 and 3 . There were no significant differences among treatments for body weight gain (BWG) and feed conversion ratio (FCR). In contrast, there was significant difference in comparison of control+ vs. control- diet $(P=0.009)$ and $0.4 \mathrm{ml}$ savory vs. control+ diet $(P=0.101)$ for body weight gain. 
Table 2. Effect of different treatments on body weight gain (BWG) of experimental broilers at different periods of experiment (g).

\begin{tabular}{lllll}
\hline Treatments & $\mathbf{2 1 - 2 8 ~ d}$ & $\mathbf{2 9 - 3 5}$ & $\mathbf{3 6 - 4 2}$ & $\mathbf{2 1 - 4 2 ~ d ~}$ \\
Control+* & 396.25 & 439.5 & 458.00 & $1293.75 a * * *$ \\
Control-** & 359.00 & 404.5 & 375.50 & $1139.25 \mathrm{~b}$ \\
Control+ + 0.4 ml savory essence & 396.00 & 459.0 & 420.25 & $1275.25 \mathrm{a}$ \\
Control- + 0.4 ml savory essence & 389.00 & 433.5 & 410.75 & $1233.25 \mathrm{ab}$ \\
SEM*** & 3.36 & 4.9 & 12.32 & 16.52 \\
Probability & 0.34 & 0.27 & 0.95 & 0.22 \\
Independent comparisons & Probability & & & \\
Control+ vs control- & $\mathrm{Ns}$ & $\mathrm{Ns}$ & $\mathrm{Ns}$ & 0.009 \\
Control+ vs savory & $\mathrm{Ns}$ & $\mathrm{Ns}$ & $\mathrm{Ns}$ & 0.101 \\
Savory vs control- & $\mathrm{Ns}$ & $\mathrm{Ns}$ & $\mathrm{Ns}$ & $\mathrm{Ns}$ \\
\hline
\end{tabular}

${ }^{*}$ Control ${ }^{+}=$The birds grown in normal temperature throughout the trial $(21-42 \mathrm{~d})$, and ${ }^{* *}$ Control $^{-}=$The birds grown in heat stress

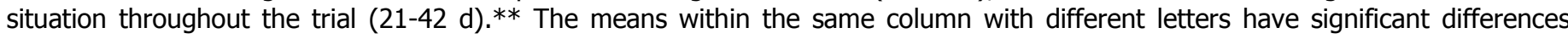
$(p \leq 0.05)$. SEM: standard error of the means

Also there was a significant difference for feed intake values among different treatments $(p \leq 0.05)$. As it shown in Table 3 the feed intakes of broilers for 3 weeks and the whole experiment period at 21 until 42 days are significantly different ( $p \leq 0.05)$ and the control+ group (basal diet with no heat stress) had the uppermost feed intake.

Table 3. Effect of different treatments on feed intake (FI) and feed conversion ratio (FCR) of experimental broilers at different weeks of experiment.

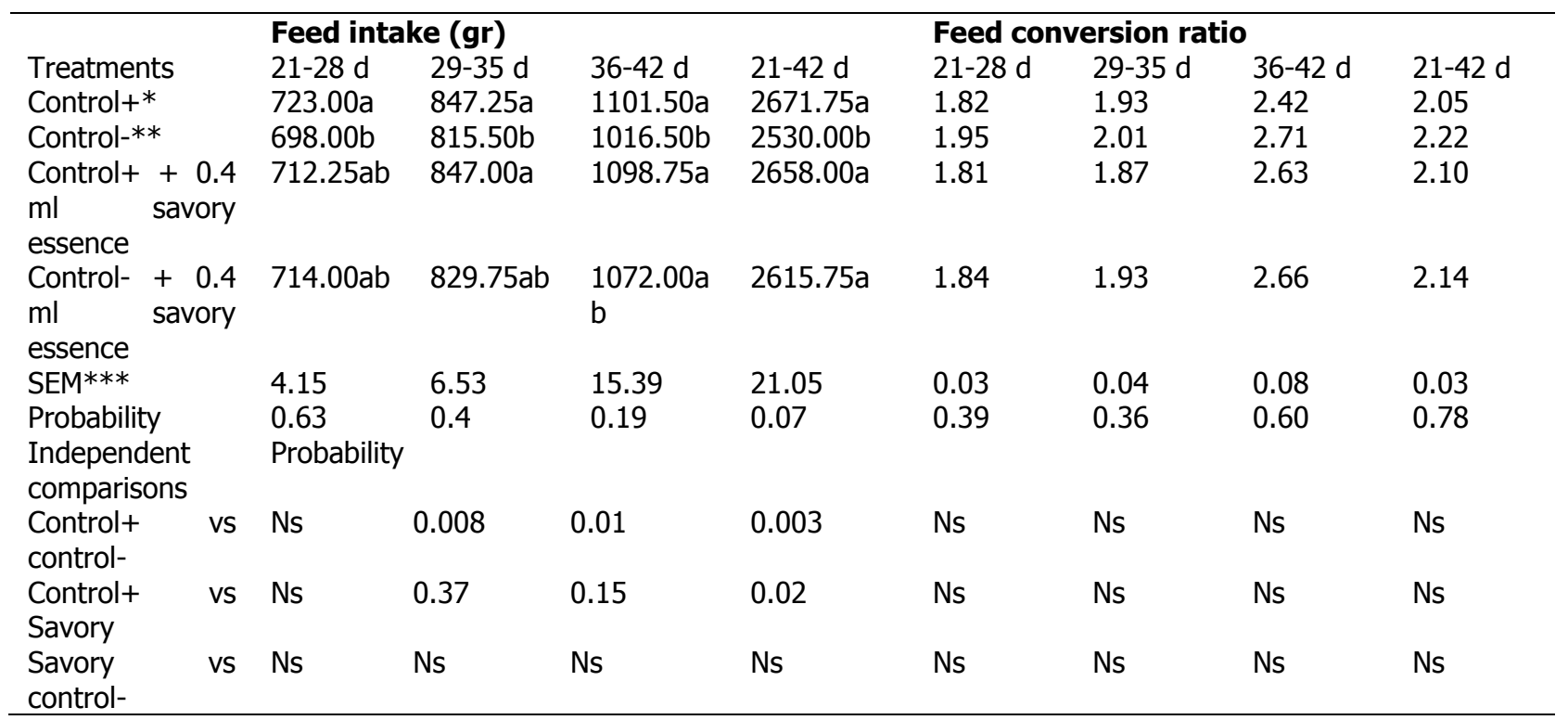

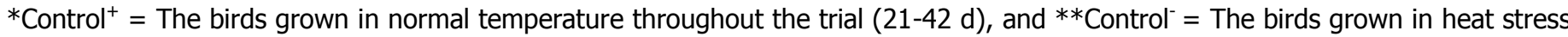
situation throughout the trial (21-42 d).** The means within the same column with different letters have significant differences $(p \leq 0.05)$. SEM: standard error of the means.

No significant differences were pointed out for relative weight of dressing, breast, thigh, liver, heart, spleen and bursa of Fabricus of experimental broilers at 42 days of age $(p \leq 0.05)$. Adding of $0.4 \mathrm{ml}$ of savory essence showed an increase on relative weight of breast and thigh in 42 days of age as compared to other treatments, but not significant $(p \leq 0.05)$. Also, liver and heart weights improved for the birds that received treated water but differences were not significant. Overall use of savory essence to 21 days had a positive effect on lymphoid organs spleen and bursa of fabricius, although this difference was not significant.

Table 4. Effect of different treatments on relative weight of dressing, breast, thigh, liver, heart, spleen and bursa of Fabricus at 42 days of age. (\% body weight).

\begin{tabular}{|c|c|c|c|c|c|c|c|}
\hline $\begin{array}{l}\text { Treatments } \\
\text { Control+* }\end{array}$ & $\begin{array}{l}\text { Dressing } \\
65.46\end{array}$ & $\begin{array}{l}\text { Breast } \\
25.16\end{array}$ & $\begin{array}{l}\text { Thighs } \\
20.92\end{array}$ & $\begin{array}{l}\text { Liver } \\
2.33\end{array}$ & $\begin{array}{l}\text { Heart } \\
0.46\end{array}$ & $\begin{array}{l}\text { Spleen } \\
0.11\end{array}$ & $\begin{array}{l}\text { Bursa } \\
0.17\end{array}$ \\
\hline Control-** & 64.59 & 24.76 & 19.33 & 2.37 & 0.44 & 0.13 & 0.18 \\
\hline $\begin{array}{ll}\text { Control+ } & + \\
0.4 & \mathrm{ml} \\
\text { savory } & \\
\text { essence } & \end{array}$ & 64.59 & 26.07 & 19.42 & 2.41 & 0.43 & 0.13 & 0.20 \\
\hline $\begin{array}{lr}\text { Control- } & + \\
0.4 & \mathrm{ml} \\
\text { savory } & \\
\text { essence } & \end{array}$ & 63.57 & 31.62 & 24.79 & 2.95 & 0.58 & 0.14 & 0.16 \\
\hline
\end{tabular}




\begin{tabular}{|c|c|c|c|c|c|c|c|c|}
\hline SEM*** & & 0.08 & 1.68 & 1.5 & 0.15 & 0.03 & 0.01 & 0.01 \\
\hline Probability & & 0.61 & 0.27 & 0.58 & 0.26 & 0.47 & 0.46 & 0.95 \\
\hline $\begin{array}{l}\text { Independen } \\
\text { comparisons }\end{array}$ & & Probability & & & & & & \\
\hline $\begin{array}{l}\text { Control+ v } \\
\text { control- }\end{array}$ & vs & ns & ns & ns & ns & ns & ns & ns \\
\hline $\begin{array}{l}\text { Control+ v } \\
\text { savory }\end{array}$ & vS & ns & ns & ns & ns & ns & ns & ns \\
\hline $\begin{array}{l}\text { Savory } \\
\text { control- }\end{array}$ & vs & ns & ns & ns & ns & ns & ns & ns \\
\hline
\end{tabular}

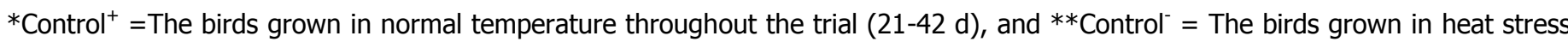
situation throughout the trial (21-42 d). ** The means within the same column with different letters have significant differences ( $p$ $\leq$ 0.05). SEM: standard error of the means.

The effects of different treatments on blood plasma glucose content and liver function that monitored by determining the activities of aspartate aminotransferase (AST), alanine aminotransferase (ALT) and alkaline phosphatase (ALP) showed in Table 5. The results indicated that the glucose, AST and ALT content of blood plasma of broilers in group 4 (Control- +0.4 ml savory essence) reduced significantly in compare with control- group $(p \leq 0.05)$. Also there was no significant difference between different treatments in ALP content of blood plasma of experimental broilers.

Table 5. Effects of different treatments on experimental broilers blood plasma activities of aspartate aminotransferase (AST), alanine aminotransferase (ALT), alkaline phosphatase (ALP) and blood plasma glucose content on 42 day of age.

\begin{tabular}{lllll}
\hline Treatments & Glucose & AST (U.L) & ALT (U.L) & ALP (U.L) \\
Control+* & $188.5 \mathrm{~b}$ & $234.25 \mathrm{~b}$ & $13.00 \mathrm{a}$ & 1400.50 \\
Control-* & $264.75 \mathrm{a}$ & $273.75 \mathrm{a}$ & $20.00 \mathrm{c}$ & 1871.75 \\
Control+ + $0.4 \mathrm{ml}$ savory essence & $189.00 \mathrm{~b}$ & $227.25 \mathrm{~b}$ & $13.75 \mathrm{bc}$ & 1672.75 \\
Control- + $0.4 \mathrm{ml}$ savory essence & $232.5 \mathrm{ab}$ & $228.75 \mathrm{~b}$ & $16.25 \mathrm{~b}$ & 1580.50 \\
SEM*** & 10.64 & 6.12 & 0.83 & 78.11 \\
Probability & 0.3 & 0.007 & 0.14 & 0.94 \\
Independent comparisons & Probability & & & $\mathrm{n}$ \\
Control+ vs control- & 0.001 & 0.02 & 0.0004 & $\mathrm{~ns}$ \\
Control+ vs savory & 0.29 & 0.03 & 0.03 & $\mathrm{~ns}$ \\
Savory vs control- & $\mathrm{ns}$ & 0.017 & $\mathrm{~ns}$ & $\mathrm{~ns}$ \\
\hline
\end{tabular}

${ }^{*}$ Control $^{+}=$The birds grown in normal temperature throughout the trial $(21-42 \mathrm{~d})$, and ${ }^{*} *$ Control $^{-}=$The birds grown in heat stress $^{2}$ situation throughout the trial $(21-42 \mathrm{~d}) . * *$ The means within the same column with different letters have significant differences $(p \leq 0.05)$. SEM: standard error of the means.

IgG measurements are shown in Table 6 . As it clear, the IgG content of chickens blood were significantly affected by different treatments on different weeks $(p \leq 0.05)$. The IgG were rise with including savory essence to drinking water of broilers and at the 42 day control $++0.4 \mathrm{ml}$ savory essence group had the highest IgG content and at 42 day the IgG extent of treatment control- +0.4 $\mathrm{ml}$ savory essence improved significantly in compare with control- group ( $\mathrm{p} \leq 0.05)$.

Table 6. Effect of different treatments on Ig G of experimental broilers at 42 day of age. (mg.ml).

\begin{tabular}{lllll}
\hline Treatments & $\mathbf{2 1 d}$ & $\mathbf{2 8 d}$ & $\mathbf{3 5 d}$ & $\mathbf{4 2 d}$ \\
Control+* & 2.35 & $1.93 \mathrm{ab}$ & $1.81 \mathrm{~b}$ & $2.03 \mathrm{a}$ \\
Control-** & 1.79 & $1.38 \mathrm{c}$ & $1.55 \mathrm{c}$ & $1.57 \mathrm{c}$ \\
Control+ + $0.4 \mathrm{ml}$ savory essence & 2.46 & $2.17 \mathrm{a}$ & $1.98 \mathrm{a}$ & $2.20 \mathrm{a}$ \\
Control- + $0.4 \mathrm{ml}$ savory essence & 1.91 & $1.65 \mathrm{bc}$ & $1.90 \mathrm{ab}$ & $1.82 \mathrm{~b}$ \\
SEM*** & 0.11 & 0.09 & 0.05 & 0.07 \\
Probability & 0.15 & 0.04 & 0.0003 & 0.005 \\
Independent comparisons & Probability & & & $2.12 \mathrm{a}$ \\
Control+ vs control- & $2.40 \mathrm{a}$ & $2.05 \mathrm{a}$ & $\mathrm{ns}$ & $1.70 \mathrm{~b}$ \\
Control+ vs savory & $1.85 \mathrm{~b}$ & $1.52 \mathrm{~b}$ & $\mathrm{~ns}$ & $2.01 \mathrm{a}$ \\
Savory vs control- & $\mathrm{ns}$ & $1.91 \mathrm{a}$ & $1.94 \mathrm{a}$ & \\
\hline
\end{tabular}

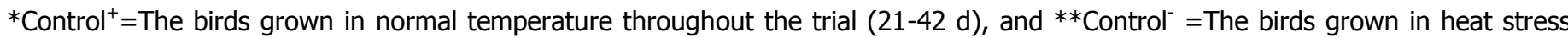
situation throughout the trial (21-42 d).** The means within the same column with different letters have significant differences $(p \leq 0.05)$. SEM: standard error of the means.

\section{Discussion}

In the current study, savory oil exhibited hopeful effects on body weight gain of the broiler chicken in days 21-42 of age when birds suffered from extreme heat stress. The savory was specified as natural product rich in essential oils and carvacrol components that practically all its characteristics could be attributed by carvacrol features (Khosravinia, 2016). It has been shown that supplementation of drinking water with 200, 300, 400 or $500 \mathrm{mg}$ per each liter savory essential oils during 1-28 days could effectively compensate their weight gain during 29-42 days of age (Khosravinia et al. 2013). Also, our findings are consistent with results of (Lee et al., 2003) who stated 2 percentage improvements in average daily gain of broiler chicken by inclusion of $0.2 \mathrm{~g}$ per 
$\mathrm{kg}$ carvacrol in the diet. Although, some reports showed no positive effects of savory on weight gain of broiler chickens (Khosravinia, 2016). However, the differences in findings might be endorsed by physiological status of the birds where in the

current study birds were raised in heat stress conditions. The improved FI for the treated birds was in agreement with the results reported by (Basmacioglu et al., 2004), who found that addition of $0.2 \mathrm{~g}$ per $\mathrm{kg}$ carvacrol and $0.15 \mathrm{~g}$ per each of kg oregano extract produced $+2 \%$ and $6 \%$ difference in FI of treated birds in compare with the control groups. The results on FI in this study were not in harmony with the findings of (Lee et al., 2003 and Khosravinia, 2016). Furthermore, the improvement in FI in this study may be due to the phytogenic properties of savory, witch there are suggestions that dietary inclusion of phytogenic foodstuffs may improve digestion processes in avian species (Mellor, 2000). The data on FCR in this study were disagreement with results of almost all other reports. These findings are to some extent in disagreement with the reports of (Lee et al., 2003) and (Basmacioglu et al., 2004) who found decreased FCR for the carvacrol received birds.

Furthermore, use of savory oil to 21 days had a positive effect on organs, although this influence was not significant. Mohammad et al. (2013) reported that, inclusion of savory essential oil for 21 days (21-42 days) in diet of heat stressed broilers had no significant effect on lymphoid organs (spleen, thymus, bursa of Fabricius) weight and our findings confirm it. Besides, in some studies performed in animal fields, the influence of medical plants on improvement of relative weights of different organs had been reported (Rivera et al., 2003; Schuberth et al., 2002). Additionally (Rahimi et al., 2011) reported that the dietary thyme extract (0.1\%) soluble in water affected relative weight of bursa of fabricius of broilers significantly. Moreover, dietary treated birds with polysavone (alfalfa extract) improved the relative thymus, bursa and spleen weights (Dong et al., 2007).

In the current study, blood glucose of experimental birds influenced by savory essence and decreased significantly, while, these observations dissimilar to (Ghazi et al., 2015) and Saadat et al. (2004) results, who reported no effect of savory on blood glucose of broilers. Disturbance of glucose metabolism in liver was suggested as a mechanism of the anti-diabetic action of savory oil, which might be related to the anti-oxidative influence of savory (Souri, 2015). Therefore any medicine to change hepatic gluconeogenesis or glycogenolysis might affect glucose homeostasis (Souri, 2015). Besides reductions in fasting blood glucose and triglyceride were reported when savory essential oil was given to diabetic and hyperlipidemic rats (Abdollahi et al., 2003).

The present results showed statistically significant demotion in activities of aspartate aminotransferase (AST) and alanine aminotransferase (ALT) with savory inclusion. Also the activity of alkaline phosphatase (ALP) was decline with savory addition to drinking water but not significantly. As it cleared, the high activities of AST, ALP and ALT in blood are bio indicators of liver damage (Rosa et al., 2001, Safameher et al., 2008, Mohamed and Mohamed, 2009 and Valchev et al., 2014) so the reduction of these hepatic enzymes with savory addition, indicated the positive effects of savory essence on reparation of liver. The immunoglobulin IgG measurements of experimental broilers showed a significant improvement in Ig G content in blood of savory treated broilers.

Souri et al. (2015) observations confirm our findings. In poultry industry, it is very imperative to improve immunity in order to avoid infectious diseases. A range of factors such as vaccination failure, infection by immunosuppressive diseases, and abuse of antibiotics can induce immunodeficiency. Application of immune stimulants is one of the solutions to improve the immunity of animals and to decrease their susceptibility to infectious disease (Chen et al. 2003). Plants rich in flavonoids such as T. vulgaris spread out the activity of vitamin C perform as antioxidants and may therefore enhance immune function (Cook and Samman, 1996 and Manach et al. 1996). The addition of 0.3 percentage of savory to broilers diet elevated chickens Newcastle disease titers because high volumes of vitamin $A$ and vitamin $E$ in this herb play a helpful role in antibody production, improving serum antibody levels and the phagocytic activity of immune cells (Tampieri et al. 2005). Flavonoids and polyphenolic complexes in savory oil exhibit several pharmacological influences, including antioxidant activity, inhibition of histamine release from mast cells and inhibition of arachidonic acid metabolism (Amresh et al., 2007). The savory essential oil extracted reversed oxidative damage to rat lymphocytes induced by hydrogen peroxide (Hajhashemi et al., 2011).

\section{Conclusion}

In conclusion, we may suggested that the inclusion of savory oil at $4 \mathrm{ml}$.L through drinking water to heat stressed broilers maybe improves economic proficiency in broiler flocks. Such advantageous properties are due to accumulation of minute advantages of savory oil in suitable feed intake and greater body weight gain and also improved IgG and lowered hepatic enzymes activities.

\section{Acknowledgements}

The authors are grateful thanks for the partial support by Urmia Branch, Islamic Azad University, and Urmia, Iran.

\section{Conflict of interest}

The authors stated no conflict of interest relating to financial and substance of study.

\section{References}

Abdollahi, M., Salehnia, A., Mortazavi, S. H., Ebrahimi, M., Shafiee, A., Fouladian F., Keshavarz K., Sorouri, S., Khorasani, R., Kazemi, A. (2003). Antioxidant, antidiabetic, antihyperlipidemic, reproduction stimulatory properties and safety of essential oil of Satureja khuzestanica in rat in vivo: A toxicopharmacological study. Med Sci Monit 9, 331-335.

Amresh, G., Reddy, G., Rao, C. V., Singh P. (2007). Evaluation of anti-inflammatory activity of Cissampelos pareira root in rats. J Ethnopharmacol. 110, 526-531.

Azaz, D., Demirci, F., Satil, F., Kurkcuoglu, M., Baser, K. H. (2002). Antimicrobial activity of some Satureja essential oils. Z Naturforsch C. 57, 817-821.

Basmacioglu, H., Tokusoglu, O., Ergul, M. (2004). The effects of oregano and rosemary essential oils or alpha-tocopheryl acetate on performance and lipid oxidation of meat enriched with n-3 PUFAs in broilers. South Afr J Anim Sci. 34, $197-210$.

Belay, T., Teeter, R. G. (1993). Broiler water balance and thermo-balance during thermoneutral and high ambient temperature exposure. Poult Sci. 72, 116-124.

Cabuk, M., Bozkurt, M., Alcicek, A., Catll, A. U., Baser, K. H. C. (2006). The effect of a mixture of herbal essential oils, a mannan oligosaccharide or an antibiotic on performance of laying hens under hot climatic conditions. S. Afr. J. Anim. Sci. 36, $135-141$.

Chen, H., Li, D., Chang, B. Y., Gong, L., Dai, J., Yi, G. (2003). Effects of Chinese herbal polysaccharides on the immunity and growth performance of young broilers. Poult. sci. 82, 364-370. 
Cook, N., Samman, S. (1996). Flavonoids-chemistry, metabolism, cardioprotective effects, and dietary sources. J. Nutr. Biochem. 7, 66-76.

Dong, X. F., Gao, W. W., Tong, J. M., Jia, H. Q., Sa, R. N., Zhang, Q. (2007). Effect of polysavone (Alfalfa extract) on abdominal fat deposition and immunity in broiler chickens. J Poult Sci. 86, 1955-1959.

Ghazi, S., Mahdavi, R., Naseri, A., Habibian, M. (2015). Effects of supplementation of Satureja khuzistanica Jamzad essential oils in the drinking water on growth performance, serum metabolites and differential counts of white blood cells in broiler chickens. Journal of Livestock Science and Technologies, 3(1), 1-10.

Hajhashemi, V., Sajjadi, S. E., Zomorodkia, M. (2011). Antinociceptive and anti-inflammatory activities of Bunium persicum essential oil, hydroalcoholic and polyphenolic extracts in animal models. Pharmacol. Biol. 49, 146-151.

Khosravinia, H. (2016). Mortality, production performance, water intake and organ weight of the heat stressed broiler chicken given savory (Satureja khuzistanica) essential oils through drinking water, Journal of Applied Animal Research, 44:1, 273-280,

Khosravinia, H., Ghasemei, S., Rafiei Alavi, E. (2013). The effect of savory (Satureja khuzistanica) essential oils on performance, liver and kidney functions in broiler chickens. J Anim Feed Sci 22, 50-55.

Lee, K. W., Everts, H., Kappert, H. J., Frehner, M., Losa, R., Beynen, A. C. (2003). Effects of dietary essential oil components on growth performance, digestive enzymes and lipid metabolism in female broiler chickens. Br Poult Sci. 44, $450-457$.

Manach, C., Regerat, F., Texier, O., Agullo, G., Demigne, C., Remesy, C. (1996). Bioavailability, metabolism and physiological impact of 4-oxo-flavonoids. Nutr Res. 16, 517-544.

Männer, K., Wang, K., (1991). Effectiviness of zinc bacitracin on production traits and energy metabolism of heat-stressed hens compared with hens kept under moderate temperature. Poult Sci. 70, 2139-2147.

May, J. D., Lott, B. D. (1992). Feed and water intake patters of broilers at high environmental temperatures. Poult Sci. 71, 331-336. Mellor, S. (2000). Nutraceuticals - alternatives to antibiotics. World Poult. 16, 14-15.

Mohamed, M. A., Mohamed, M. H. (2009). Haemato-biochemical and pathological studies on aflatoxicosis and treatment of broiler chicks in Egypt. Veterinaria Italiana, 45, 323-337.

Mohammad, M., Vahid, A., Masoud, P. (2013). Supplementation effect of Satureja essential oils in drinking water on immune conduct of broiler chickens reared under stress of heat. Global Journal of Animal and Environmental Biology. 1(1), $001-004$.

Radonic, A., Milos, M. (2003). Chemical composition and in vitro evaluation of antioxidant effect of free volatile compounds from Satureja montana L. Free Radical Res. 37, 673-679.

Rahimi, S., Teymouri, Zadeh Z., Karimi Torshizi, M. A, Omidbaigi, R., Rokni, H. (2011). Effect of the three herbal extracts on growth performance, immune system, blood factors and intestinal selected bacterial population in broiler chickens. J Agri Sci Tech 13, 527539.

Rivera, E., Hu, S. (2003). Ginseng and aluminium hydroxide act synergistically as vaccine adjuvants. Vaccine, 21, $1149-1157$.

Rosa, C. A. R., Miazzo, R., Magnoli, C., Salvano, M., Chiacchiera, S. M., Ferrero, S., Saenz, M., Carvalho, E. C. Q., Dalcero, A. (2001). Evaluation of the efficacy of bentonite from the south of Argentina to ameliorate the toxic effects of aflatoxin in broilers. Poultry Science, 80, 139-144.

Ross 308 broiler. (2007). Nutrition specification. Available in: www.aviagen.com.

Saadat, M., Pournourmohammadi, S, Donyavi, M., Khorasani, R., Amin, G., Salehnia, A. N., Abdollahi, M. (2004). Alteration of rat hepatic glycogen phosphorylase and phosphoenolpyruvate carboxykinase activities by Satureja khuzestanica Jamzad essential oil. J Pharm Pharmacol. Sci. 7, 310-314.

Safameher, A. (2008). Effects of clinoptilolite on performance, biochemical parameters and hepatic lesions in broiler chickens during aflatoxicosis. Journal of the American Veterinary Medical Association, 7, 381-388.

Schuberth, H. J, Riedel Caspari, G. (2002). Flow cytometric testing of immunological effects of a phytomedicinal combination (EquiMun) and its compounds on bovine leucocytes. J Vet Med 49(6), 291-298.

Souri, H., Khatibjoo, A., Taherpoor, K., Hassan Abadi, A., Fattahnia, F., Askari, M. (2015). Effect of Thymus vulgaris and Satureja khuzestanica ethanolic extracts on broiler chickens' performance and immune response. Iranian Journal of Applied Animal Science 5 , 437-446.

Suderman, A., Solikhah, S. H. (2011). Performance and meat cholesterol content of broiler chickens fed Pluchea indica L. leaf meal reared under stress condition. Media Peternakan. 43, 64-68.

Tampieri, M. P., Galuppi, R., Macchioni, F., Carelle, M. S., Falcioni, L., Cioni, P. L. Morelli, I. (2005). The inhibition of Candida albicans by selected essential oils and their major components. Mycopathologia. 159, 339-345.

Valchev, I., Kanakov, D., Hristov, T. S., Lazarov, L., Binev, R., Grozeva, N., Nikolov, Y. (2014). Investigations on the liver function of broiler chickens with experimental aflatoxicosis. Bulgarian Journal of Veterinary Medicine, 17(4).

Zeinali, A., Kermanshahi, H., Riasi, A., Farhangfar, H., Sarir, H., Ziaie, H. (2011). Effects of sodium selenite and turmeric powder on thyroid hormones and plasma lipids of broiler chickens reared under heat stress condition. Global Veterinaria. 6, $237-240$.

\section{Citation:}

Mohammad Yadegari, Hasan Ghahri and Mohsen Daneshyar. (2019). Efficiency of Savory (Satureja Khuzestanica Jamzad) Essential Oil on Performance, Carcass traits, Some Blood Parameters and Immune Function of Male Ross 308 Heat Stressed Broiler Chicks. Ukrainian Journal of Ecology, 9(4), 515-520.

(cc) $\mathrm{Er}$ This work is licensed under a Creative Commons Attribution 4.0. License 